\title{
Left ventricular mycotic mass and diffuse mycotic myocarditis in a patient with hemophagocytic syndrome - case report
}

\author{
Matija Marković*, Njetočka Gredelj Šimec, Tomislav Letilović, Ana Planinc-Peraica, \\ Slobodanka Ostojić Kolonić \\ University Hospital Merkur, Zagreb, Croatia
}

Zygomicosis is a fungal disease caused by fungi from the Zygomycota order that are usually airborne spread, with pulmonary and rhinocerebral involvement being the most common. Once in the bloodstream, spores tend to accumulate in vascular tissues leading to thrombosis, infarction, and necrosis of involved tissues.

In immunocompromised patients, such as those with hemophagocytic syndrome, zygomicosis is frequently characterized by fulminant disseminated disease, with a $80 \%$ mortality rate.

We present a 45-year old patient with hemophagocytic syndrome who was treated with steroids, etoposide, and cyclosporine. Two months after the initial treatment, the patient was admitted for a respiratory infection, and was treated with antibiotics and antiviral drugs with a good clinical and laboratory response to the therapy. On the tenth day there

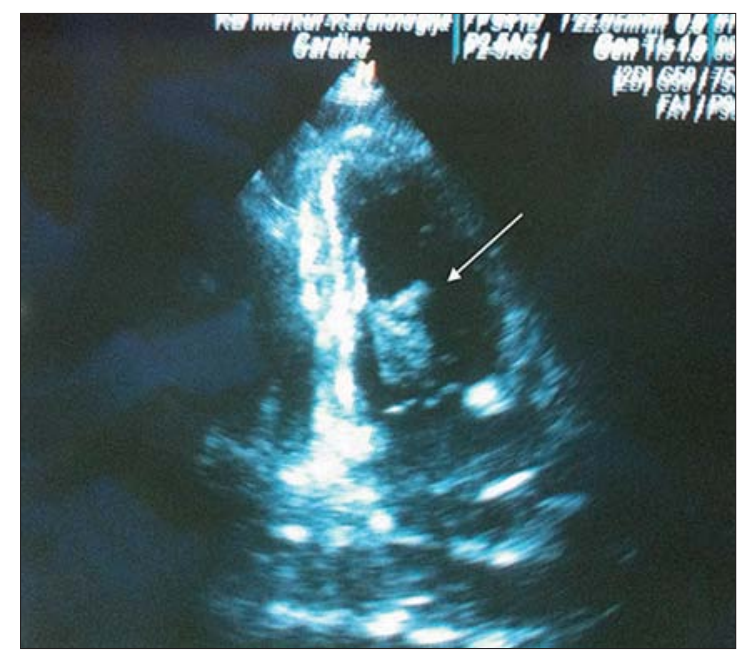

Figure 1. Apical view showing a left ventricular mass, later proven to be a zygomycotic mass. was a sudden clinical deterioration with signs of left-sided heart failure, elevated troponin levels, and ECG showing a complete AV block. Right-sided hemiparesis and elevated inflammatory parameters were also present. A temporary pacemaker was placed. A brain MDCT was performed and multiple ischemic and hemorrhagic lesions were found. Emergency echocardiography study showed a semi-mobile, peduncular mass in the left ventricle. It originated from the anterior mitral leaflet, measuring $4 \times 2 \mathrm{~cm}$ and protruding to the LV cavity. There were no disorders of myocardial contractility, and ejection fraction was 60\% (Figure 1). Echocardiographic features of the mass resembled a myxoma. The patient died three hours later from multiple organ dysfunction syndrome. Autopsy showed disseminated zygomicosis infecting the heart with a mycotic mass in left ventricle. The leptomeninges, brain, and lungs were also infected.

Primary heart tumors are rare, accounting for 0.0017-0.19\% on unselected biopsies. In immunocompromised patients with a new heart mass, a mycotic mass as a sign of disseminated mycosis should be considered before a primary heart tumor in order to start appropriate treatment. Mortality of patients with disseminated zygomycosis and heart mass is very high and survival is only possible with a combined surgical and antimicrobial approach. The diagnosis of disseminated zygomycosis was considered however due to the patient's abrupt clinical deterioration, and fulminant course cardiothoracic treatment could not to be arranged.

KEYWORDS: zygomycoses, cardiac tumors, intracavitary tumors of the heart, hemophagocytic syndrome.

\section{Received: $20^{\text {th }}$ Mar 2013}

*Address for correspondence: Klinička bolnica Merkur, Zajčeva 19, HR-10000 Zagreb, Croatia.

Phone: +385-1-2431-390

E-mail: mtj.markovic@gmail.com

\section{Literature}

1. Roden MM, Zaoutis TE, Buchanan WL, et al. Epidemiology and outcome of zygomycosis: a review of 929 reported cases. Clin Infect Dis. 2005;41(5):634-53.

2. Reynen K. Frequency of primary tumors of the heart. Am J Cardiol. 1996;77(1):107.

3. Mantadakis E, Samonis G. Clinical presentation of zygomycosis. Clin Microbiol Infect. 2009;15 Suppl 5:15-20.

4. van de Glind GJ, Gidding CE, Verlaat CM, et al. Acute cardiac failure due to intra-atrial mass caused by zygomycetes in an immunocompromised paediatric patient. Case Rep Med. 2010;2010: 241791. 